\title{
Research Paper: Pharmacological and Molecular Evidence of Neuroprotective Curcumin Effects Against Biochemical and Behavioral Sequels Caused by Methamphetamine: Possible Function of CREB-BDNF Signaling Pathway
}

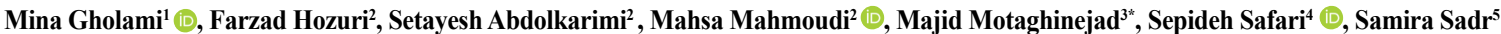 \\ 1. Department of Medicinal Chemistry, School of Pharmacy, Tehran University of Medical Sciences, Tehran, Iran. \\ 2. Department of Pharmaceutical Chemistry, Faculty of Pharmaceutical Chemistry, Pharmaceutical Sciences Branch, Islamic Azad University, \\ Tehran, Iran. \\ 3. Research Center for Addiction and Risky Behaviors (ReCARB), Iran Psychiatric Center, Iran University of Medical Sciences, Tehran, Iran. \\ 4. Razi Drug Research Center, Iran University of Medical Sciences, Tehran, Iran. \\ 5. Department of Research and Development, Parsian-Exir-Aria Pharmaceutical Company, Tehran, Iran.
}

\begin{tabular}{|c|c|}
\hline $\begin{array}{l}\text { Use your device to scan } \\
\text { and read the article online }\end{array}$ & Citation: Gholami, M., Hozuri, F., Abdolkarimi, S., Mahmoudi, M., Motaghinejad, M., \& Safari, S., et al. (2021). Pharmacological \\
\hline arpin: & $\begin{array}{l}\text { and Molecular Evidence of Neuroprotective Curcumin Effects Against Biochemical and Behavioral Sequels Caused by Metham- } \\
\text { phetamine: Possible Function of CREB-BDNF Signaling Pathway. Basic and Clinical Neuroscience, 12(3), 325-338. http://dx.doi. } \\
\text { org/10.32598/bcn.2021.1176.3 }\end{array}$ \\
\hline 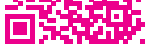 & dol'http://dx.doi.org/10.32598/ben.2021.1176.3 \\
\hline
\end{tabular}

\section{Article info:}

Received: 15 Dec 2018

First Revision: 20 Feb 2019

Accepted: 20 Apr 2020

Available Online: 01 May 2021

Keywords:

Methamphetamine, Curcumin, Neurodegeneration, Cyclic AMP response element binding protein, Brain-derived neurotrophic factor

\section{ABSTRACT}

Introduction: The neuroprotective impact of curcumin and the role of CREB (Cyclic AMP Response Element Binding protein)-BDNF (Brain-Derived Neurotrophic Factor) signaling pathway was evaluated in Methamphetamine (METH)-induced neurodegeneration in rats.

Methods: Sixty adult male rats were randomly divided into 6 groups. While normal saline and $10 \mathrm{mg} / \mathrm{kg}$ METH were administered intraperitoneally in groups 1 and 2, groups 3, 4, 5, and 6 received METH $(10 \mathrm{mg} / \mathrm{kg})$ and curcumin $(10,20,40$, and $80 \mathrm{mg} / \mathrm{kg}$, respectively) simultaneously. Morris water maze test was administered, and oxidative hippocampal, antioxidant, inflammatory, apoptotic, and CREB and BDNF were assessed.

Results: We found that METH disturbs learning and memory. Concurrent curcumin therapy (40 and $80 \mathrm{mg} / \mathrm{kg}$ ) decreased cognitive disturbance caused by METH. Multiple parameters, such as lipid peroxidation, the oxidized form of glutathione, interleukin 1 beta, tumor necrosis factor-alpha, and Bax were increased by METH therapy, while the reduced type of glutathione, Bcl-2, P-CREB, and BDNF concentrations in the hippocampus were decreased.

Conclusion: Different doses of curcumin adversely attenuated METH-induced apoptosis, oxidative stress, and inflammation but enhanced the concentrations of P-CREB and BDNF. The neuroprotection caused by curcumin against METH-induced neurodegeneration is mediated through P-CREB-BDNF signaling pathway activation. 


\section{Highlights}

- Curcumin counteracts methamphetamine-induced neurodegeneration in rat hippocampus.

- Curcumin neutralizes methamphetamine-induced behavioral changes in adult rats.

- Curcumin nullifies methamphetamine-induced $\mathrm{CREB} / \mathrm{BDNF}$ changes in protein levels in rat hippocampus.

- Neuroprotective effects of curcumin against methamphetamine might be mediated by CREB/BDNF signaling pathway.

\section{Plain Language Summary}

Methamphetamine chronic abuse may induce changes in behavior such as anxiety and depression, as well as cognitive (learning and memory) dysfunction in the experimental rodent model. Abuse of this psychostimulant induces oxidative stress, inflammation, apoptosis, and brain cell damage. Curcumin is an active compound and herbal containing flavonoids with antioxidant, neuroprotection, anti-depressant, anti-inflammatory, anti-apoptotic and immunomodulatory effects. Curcumin can recover the hippocampus from neuronal damage caused by methamphetamine. Current results have shown that curcumin can prevent oxidative stress, inflammation, apoptosis, and behavioral changes induced by methamphetamine. Curcumin induces neuroprotection against neurodegeneration caused by methamphetamine.

\section{Introduction}

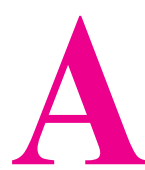

$\mathrm{s}$ a major neurotrophic factor, the BrainDerived Neurotrophic Factor (BDNF) facilitates the growth and regeneration of neurons. Brain regions known for regulating attention, emotions, and rewards express the elevated levels of BDNF (Hattiangady, Rao, Shetty \&

Shetty, 2005; Lee et al., 2005). Cyclic AMP Response Element Binding protein (CREB), as the main transcription factor, regulates the genes involved in synaptic and neural survival, neuroprotection, and neural plasticity, such as BDNF (Motaghinejad, Motevalian, Abdollahi, Heidari \& Madjd, 2017; Motaghinejad et al., 2017). Neuroprotection is regulated by various drugs, such as herbal or natural compounds with therapeutic potential. The therapeutic potential of natural flavonoids and their derivatives is generally considered against neurodegenerative disorders and certain substance abuse-induced neurodisorder (Kim, 2005; Phani Kumar \& Khanum, 2012). Other than flavonoids, phenols such as curcumin (diferuloylmethane) have antioxidant (Raza, John, Brown, Benedict \& Kambal, 2008), anti-depressant, anti-inflammatory, anti-apoptotic and immunomodulatory activity (Kuhad, Pilkhwal, Sharma, Tirkey \& Chopra, 2007; Zbarsky et al., 2005). As confirmed by biochemical research of diseases such as Alzheimer and Parkinson, curcumin therapy protects against oxidative stress by reducing lipid peroxidation and increasing antioxidant enzyme activity, such as superoxide dismutase
(SOD) and catalase (Kuhad et al., 2007; Tiwari \& Chopra, 2012; Zbarsky et al., 2005). Increased concentrations of alcohol-induced Tumor Necrosis Factor-ш (TNF-5-007) and Interleukin (IL)-1 $\beta$ are also decreased by curcumin chronic therapy (Darvesh et al., 2012; Kuhad et al., 2007). These characteristics contribute to the potential therapeutic effect of curcumin for neurodegenerative diseases, but its exact mechanism is unknown (Darvesh et al., 2012; Kuhad et al., 2007).

In this study, we used Methamphetamine (METH), a drug that its abuse has risen in recent years (Barr et al., 2006; Darke, Kaye, McKetin \& Duflou, 2008). The impacts of METH's chronic use and its biochemical and behavioral consequences remain unclear (Barr et al., 2006; Darke et al., 2008). METH induces the release into synaptic terminals of dopamine, norepinephrine and, to a lower degree of serotonin (Thrash, Karuppagounder, Uthayathas, Suppiramaniam \& Dhanasekaran, 2010; Volkow et al., 2001). This causes receptor hyperstimulation at acute stages and also decreases its receptor regulation at chronic stages (Thrash et al., 2010; Volkow et al., 2001). Functionally and pharmacologically, METH is similar to cocaine, resulting in increased potential levels of abuse and addiction (Thrash et al., 2010). In the experimental rodent model, chronic METH abuse can cause behavioral changes such as behavioral anxiety and depression, as well as cognitive (learning and memory) diseases (Brecht, O'Brien, von Mayrhauser \& Douglas Anglin, 2004; Narita, Aoki, Takagi, Yajima \& Suzuki, 2003). Experimental studies have confirmed 
the prospective impact of METH on neurodegeneration in certain brain regions, such as the hippocampus responsible for memory and anxiety (Narita et al., 2003). METH abuse may contribute apoptotic protein production such as Bax, caspase 3,8 , and 9 with fragmentation of DNA occurring in brain regions including hippocampus and amygdala, as confirmed in previous studies (Cadet, Jayanthi \& Deng, 2005; Wu et al., 2007). METH and other compounds of neuro-stimulants in brain cells may cause inflammation, oxidative stress and mitochondrial dysfunction (Jumnongprakhon, Govitrapong, Tocharus \& Tocharus, 2016; Zhang, Banerjee, Banks \& Ercal, 2009). In certain brain regions such as the hippocampus (CA1, CA2, CA3, and DG) and the amygdala, the neurotoxicity caused by METH is more noticeable (Gonçalves et al., 2010; Jumnongprakhon et al., 2016; Yamamoto \& Raudensky, 2008). Our research aimed to evaluate Curcumin's neuroprotective properties against METH induced hippocampal damage and to conclude the role of P-CREB-BDNF signaling pathway in this defense. It is proposed that curcumin play a role in protecting hippocampal and frontal neurons from stressinduced damage via CREB and BDNF up-regulation; a hypothesis that has yet to be confirmed.

\section{Methods}

\subsection{Study animals}

Sixty adult Wistar male rats, weighing between 250-300 $\mathrm{g}$, were bought from the laboratory house at the Iran University of Medical Sciences. The room temperature was controlled $\left(22 \pm 0.5^{\circ} \mathrm{C}\right)$ under the $12 \mathrm{~h} \mathrm{light} / \mathrm{dark}$ cycle. The free access to food and water was also totally provided for them.

\subsection{Study drugs}

Curcumin and METH, obtained from Sigma Aldrich (USA), were dissolved just before administration in a normal saline.

\subsection{Experimental design}

- Group 1 (control group) received normal saline (0.2 $\mathrm{ml} / \mathrm{rat}$, i.p) for a period of 21 days, and group 2 (METH) received METH (10 mg/kg, i.p) for 21 days.

- Groups 3, 4, 5, and 6 received combined doses of METH $(10 \mathrm{mg} / \mathrm{kg}$, i.p.) and curcumin $(10,20,40$, and 80 $\mathrm{mg} / \mathrm{kg}$, i.p., respectively). It should be mentioned that Curcumin's administration was preliminary in these groups, and then METH was administered after one hour. The dose of methamphetamine used for the initiation of neurodegen- eration and neuroprotective curcumin doses were chosen based on previous similar experimental studies (Belviranl1, Okudan, Atalık \& Öz, 2013; Carmena et al., 2015; Levi et al., 2012; Yadav et al., 2010; Zhao et al., 2010).

The Morris Water Maze (MWM) task, a common therapeutic approach to learning and memory testing, was conducted on the animals on the $17^{\text {th }}$ and $21^{\text {st }}$ days. After the $22^{\text {nd }}$ day, all animals were sacrificed, and their hippocampal tissue was tested for oxidative stress, inflammation, and apoptosis. Considering the importance of CREB signaling and its product BDNF, we studied the impact of curcumin on METH-mediated disturbances through the CREB signaling pathway in hippocampal tissues.

\subsection{Behavioral method}

\subsubsection{Morris Water Maze (MWM)}

MWM was conducted as a standard cognitive method for assessing cognition and spatial memory based on previous research. In this experiment, the time of escape latency, defined by the time spent to find the hidden platform and the distance traveled, determined by the distance of each animal spent to reach the hidden platform and the percentage of animal presence in the target quarter was evaluated (Motaghinejad, Motevalian, Fatima, Hashemi \& Gholami, 2017; Vorhees \& Williams, 2006).

\subsection{Molecular atudy}

\subsubsection{Mitochondrial preparations}

As mentioned above, all animals were anesthetized with 50 $\mathrm{mg} / \mathrm{kg}$ sodium thiopental IP, and the total hippocampus tissue was isolated. Subsequently, the mitochondria of the hippocampal cells were isolated and prepared by standard protocol according to previous studies (Motaghinejad et al., 2017; Motaghinejad et al., 2017; Vorhees \& Williams, 2006).

\subsubsection{Determination of oxidative stress parameters}

Level of lipid peroxidation, Malondialdehyde (MDA) production, SOD, Glutathione Peroxidase (GPx) and Glutathione Reductase (GR) activities, the amount of reduced form, protective from, the oxidized form, and toxic form (GSSG) of Glutathione (GSH) were measured as mentioned above in the standard protocols (Motaghinejad 2017; Motaghinejad, Motevalian, Fatima, Beiranvand \& Mozaffari, 2017; Motaghinejad et al., 2017; Motaghinejad, Seyedjavadein, Motevalian \& Asadi, 2016). 


\subsubsection{Measurement of protein expression}

We studied the expression or level of protein CREB (both activated [phosphorylated] and inactivated [total from]) BDNF, Akt-1 (both activated [phosphorylated] and inactivated [total from]), GSK3 (both activated [phosphorylated] and inactivated [total from]), Tumor Necrosis Factor (TNF)- $\alpha$, Interleukin (IL)-1 $\beta$, Bax, and $\mathrm{Bcl}-2$ in isolated hippocampus by ELISA commercial kits (MyBioSource, San Diego, USA) according to previous studies (Chen et al., 2004; Motaghinejad, Motevalian, Fatima, Faraji \& Mozaffari, 2017). IL-1 $\beta$, TNF- $\alpha$, Bax and Bcl-2 levels were identified as $\mathrm{ng} / \mathrm{mL}$; also BDNF and both types of CREB, Akt-1, GSK3 levels were reported as $\mathrm{pg} / \mathrm{mL}$ in hippocampus tissue suspensions (Arican, Aral, Sasmaz \& Ciragil, 2005; Demircan, Safran, Soylu, Ozcan \& Sizmaz, 2006; Lee, Kim, Park \& Kim, 2007; Shi et al., 2010).

\subsubsection{Statistical analysis}

The data analysis was carried out in GraphPad PRISM v. 6 , and the test group was evaluated by ANOVA. The group averages are compared with the Tukey test at substantial level of less than 0.001 to assess the severity of the behavior.

\section{Results}

3.1. Escape latency, traveled distance and swimming speed assessment in Morris Water Maze (MWM) training period

Comparing to the control groups, METH $(10 \mathrm{mg} / \mathrm{kg})$ induces a noticeable increase in escape latency and traveled distance during the 4-day MWM training period $(\mathrm{P}<0.001)$ (Figure 1A \& B). In contrast to METH (10 $\mathrm{mg} / \mathrm{kg}$ ) received group, all different curcumin doses inhibited METH, leading to a significant reduction in escape latency and distance travel $(\mathrm{P}<0.001)$ (Figure $1 \mathrm{~A} \&$ $\mathrm{B})$. No changes in swimming speed were noticed during animal group training (Figure 1C).

3.2. Evaluation of target quarter percentage in probe trial of Morris Water Maze (MWM)

Compared to the control groups, $10 \mathrm{mg} / \mathrm{kg}$ of METH caused a noticeable reduction in the percentage of animal presence in the target quarter $(\mathrm{P}<0.001)$ (Figure 1D). Also, curcumin can significantly reduce the METH-mediated decrease in the presence of animals in the target quarter at all doses (Figure 1D).
3.3. Curcumin diverse doses effect on METHcaused oxidative stress

METH therapy $(10 \mathrm{mg} / \mathrm{kg})$ significantly reduced mitochondrial GSH content and reduced SOD, GPx, and GR while increasing the MDA and GSSG levels compared to the control group. On the contrary, high doses of curcumin (40 and $80 \mathrm{mg} / \mathrm{kg}$ ) increased the GSH content and SOD, GPx, and GR activity, reducing the MDA and GSSG levels in METH-received animals relative to the controls $(\mathrm{P}<0.001)$ (Figure 2).

\subsection{Effects of curcumin different doses on METH- caused elevation of inflammatory biomarkers}

METH $(10 \mathrm{mg} / \mathrm{kg})$ increases the levels of IL-1 $\beta$ and TNF- $\alpha$ substantially compared to the control group $(\mathrm{P}<0.001)$ (Figure 3). On the contrary, high doses of curcumin (40 and $80 \mathrm{mg} / \mathrm{kg}$ ) stopped the METH-mediated increase in the IL-1 $\beta$ and TNF- $\alpha$ levels compared to just the METH obtained group $(\mathrm{P}<0.001)$ (Figure 3 ).

3.5. Effects of curcumin different doses on METHcaused modifications in Bax, Bcl-2, CREB, and BDNF proteins level

METH $(10 \mathrm{mg} / \mathrm{kg})$ treatment increased Bax protein expression and decreased Bcl-2, BDNF, and CREB protein expression (total and phosphorylate forms) compared to the control group $(\mathrm{P}<0.001)$ (Figure 4). On the contrary, high doses of curcumin ( 40 and $80 \mathrm{mg} / \mathrm{kg}$ ) increased Bcl-2, BDNF, and CREB (total and phosphorylate form) but decreased Bax protein expression compared to positive controls $(\mathrm{P}<0.001)$ (Figure 4).

\section{Discussion}

This research was conducted to evaluate curcumin neuroprotection against hippocampal impairment induced by METH. Chronic METH administration at a dosage of $10 \mathrm{mg} / \mathrm{kg}$ may increase escape latency and distance travel in MWM according to our study, indicating that METH administration may reduce learning performance. Also, METH administration in the probe trial reduced the percentage of presence in the aimed quarter of MWM, chronic use of the METH may reduce memory. The same result approved in the former study indicating prolonged administration of METH reduced learning and memory in rats (Cadet et al., 2005; Gonçalves et al., 2010). METH-induced dopamine, serotonin, and adrenaline to release into the brain, leading to downregulation of mentioned amine receptors, resulting in cognition impairment (Gonçalves et al., 2010; Johnson et al., 
$1(\mathrm{~A})$

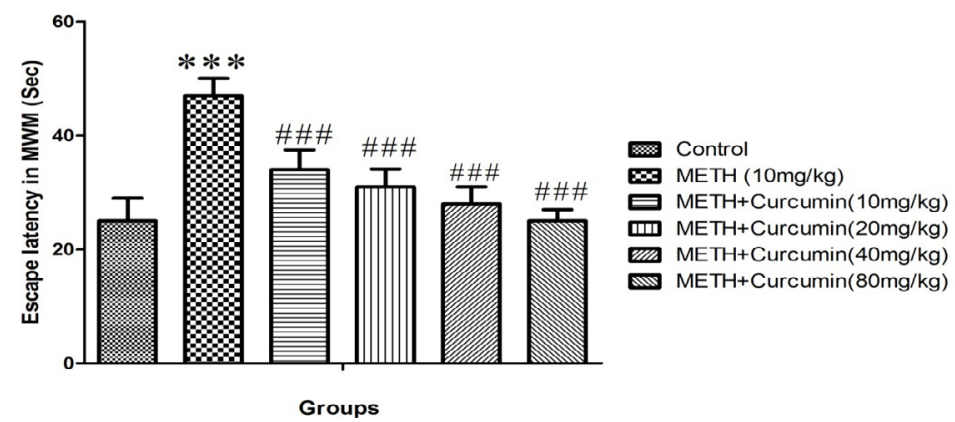

1(B)

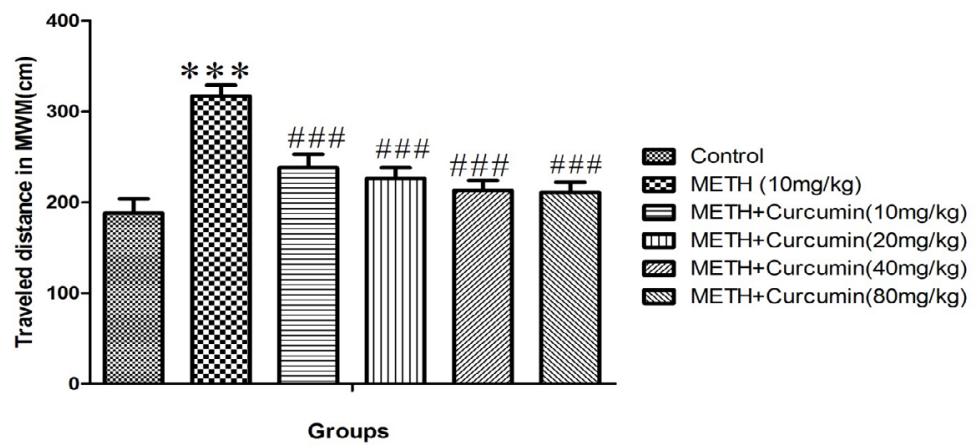

$1(\mathrm{C})$

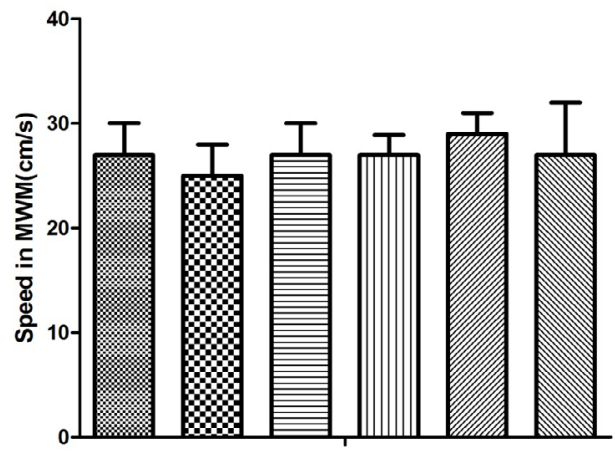

.

$\rightarrow \mathrm{METH}(10 \mathrm{mg} / \mathrm{kg})$

曰 METH+Curcumin $(10 \mathrm{mg} / \mathrm{kg}$ )

四 METH+Curcumin $(20 \mathrm{mg} / \mathrm{kg})$

mEn METH+Curcumin $(40 \mathrm{mg} / \mathrm{kg}$ )

METH+Curcumin $(80 \mathrm{mg} / \mathrm{kg}$ )

Groups

1(D)

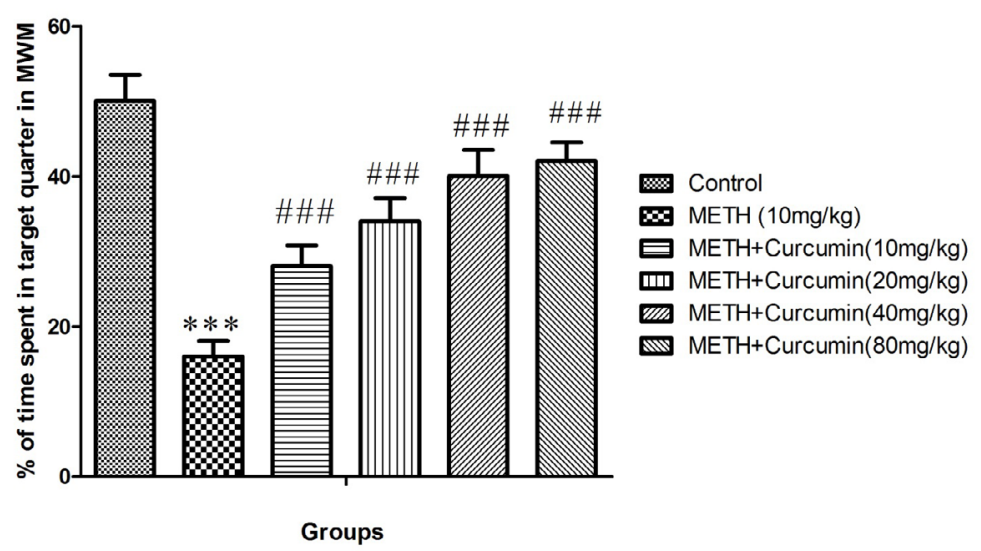

NEUR:SCIENCE

Figure 1. Escape latency, traveled distance and swimming speed assessment in Morris Water Maze (MWM) training period

A: Escape latency mean; B: Traveled distance mean; C: Swimming speed mean; and D: Spent time percentage in target quarter of probe trial in the control group and treatment groups receiving $10 \mathrm{mg} / \mathrm{kg}$ of METH and $10 \mathrm{mg} / \mathrm{kg}$ of METH in combination with curcumin 10, 20, 40, and $80 \mathrm{mg} / \mathrm{kg}$ doses across all training days using Morris Water Maze (MWM) in rats.

All data are expressed as Mean $\pm \mathrm{SEM}(\mathrm{n}=8) ;{ }^{*+* x} \mathrm{P}<0.05 \mathrm{vs}$ control; ${ }^{\# \# \#} \mathrm{P}<0.05 \mathrm{vs} 10 \mathrm{mg} / \mathrm{kg}$ of Methamphetamine (METH). 
2(A)

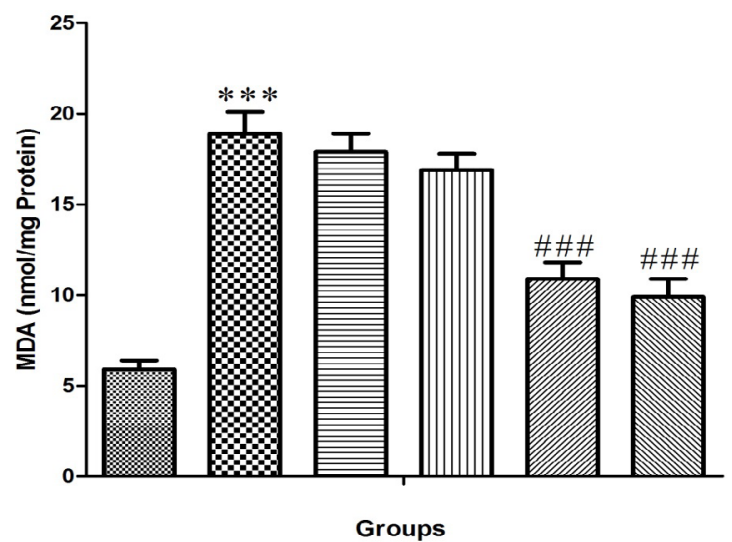

2(B)

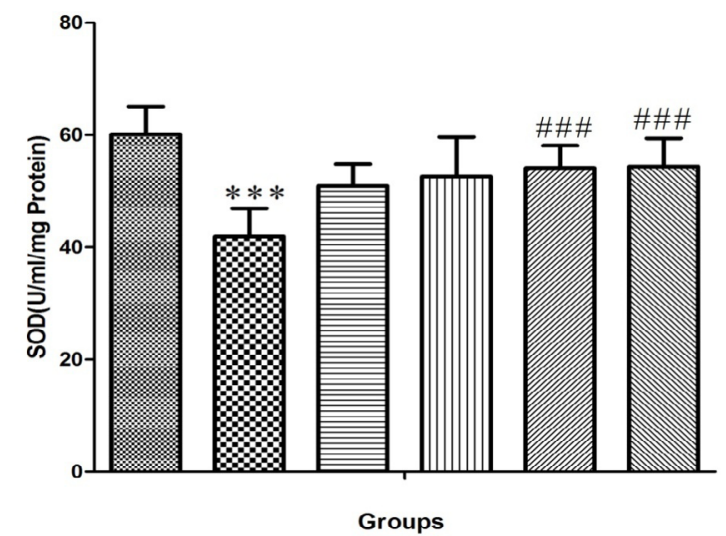

2(C)

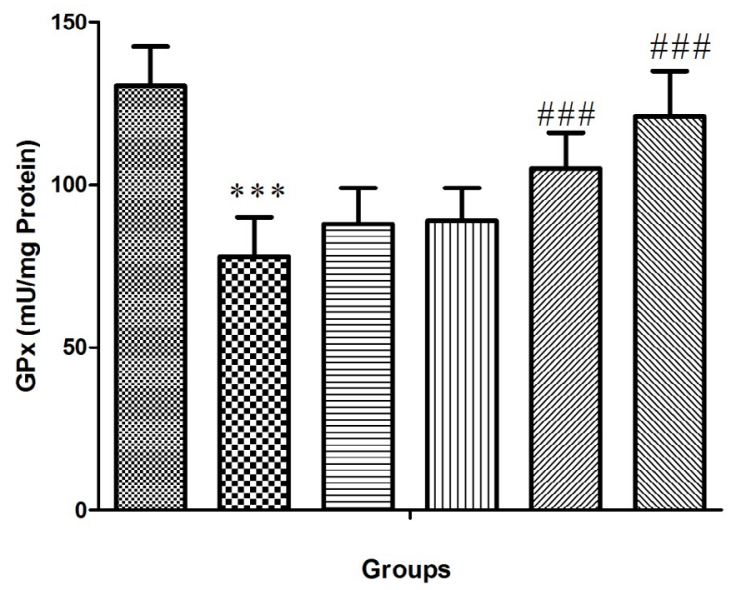

2(D)

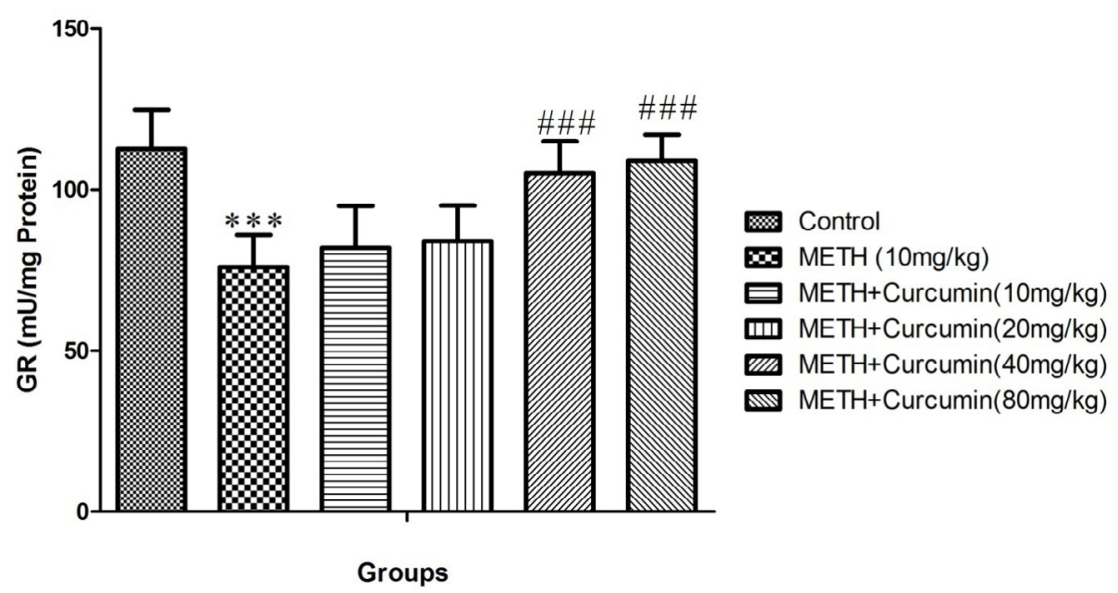


2(E)

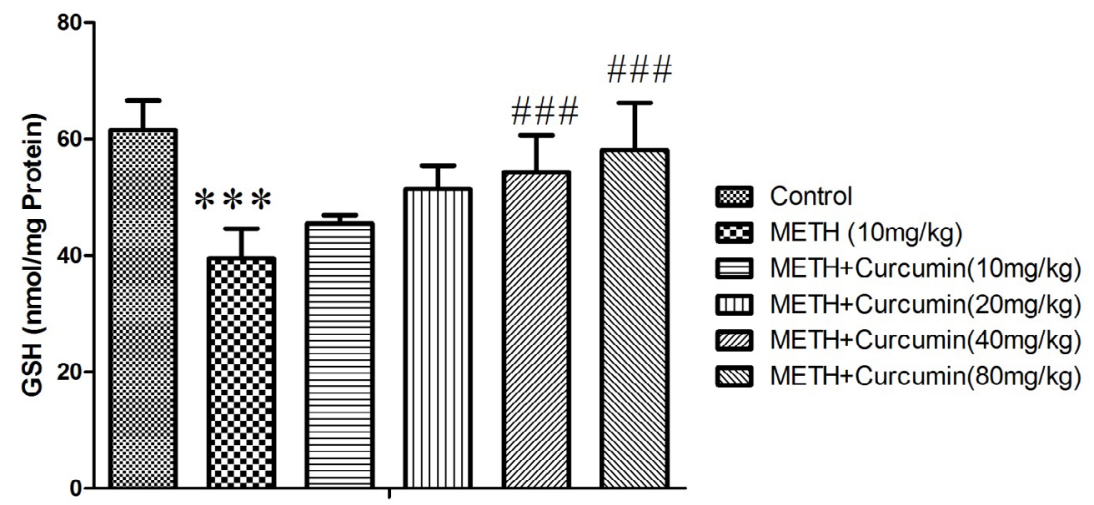

2(F)

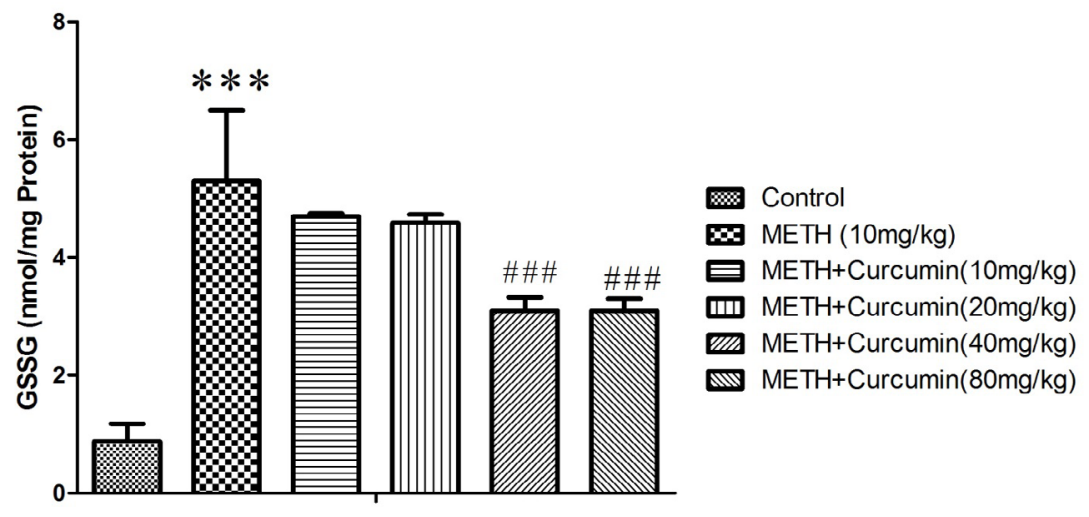

Groups

2(G)

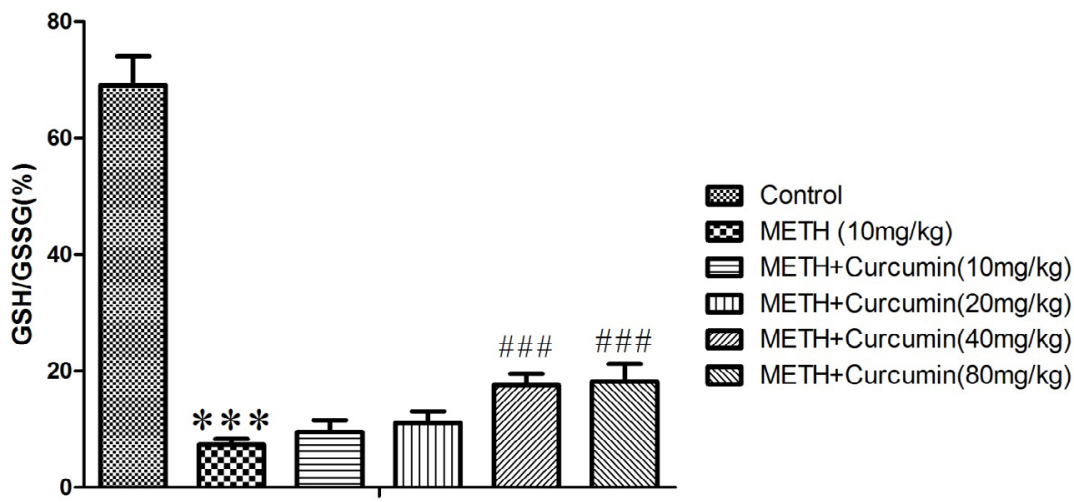

Groups

Figure 2. Curcumin diverse doses effects $(10,20,40$, and $80 \mathrm{mg} / \mathrm{kg})$

NEUR SCIENCE

A: METH-induced lipid peroxidation; B: SOD activity; C: GPx activity; D: GR activity; E: GSH; F: GSSG; and G: GSH/GSSG ratio in rats isolated hippocampus.

All data are expressed as Mean \pm SEM ( $\mathrm{n}=8) ;{ }^{* * *} \mathrm{P}<0.05$ vs control; ${ }^{\# \#} \mathrm{P}<0.05 \mathrm{vs} 10 \mathrm{mg} / \mathrm{kg}$ of Methamphetamine (METH).

SOD: Superoxide Dismutase; GPx: Glutathione Peroxidase; GR: Glutathione Reductase; GSH: Glutathione; GSSG: toxic Glutathione. 
3(A)

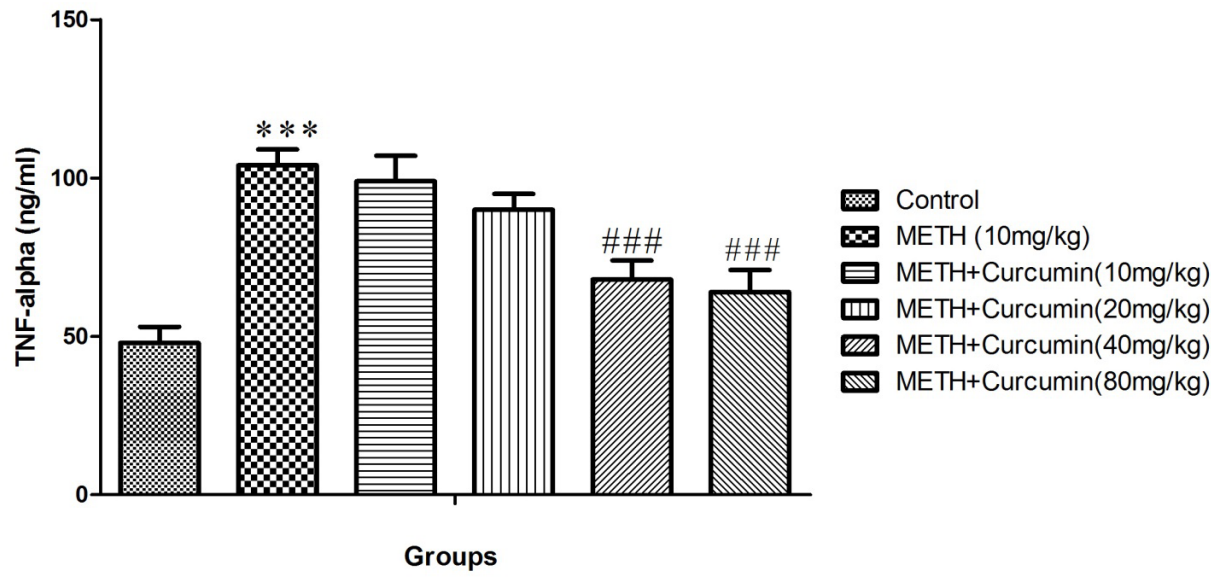

3(B)

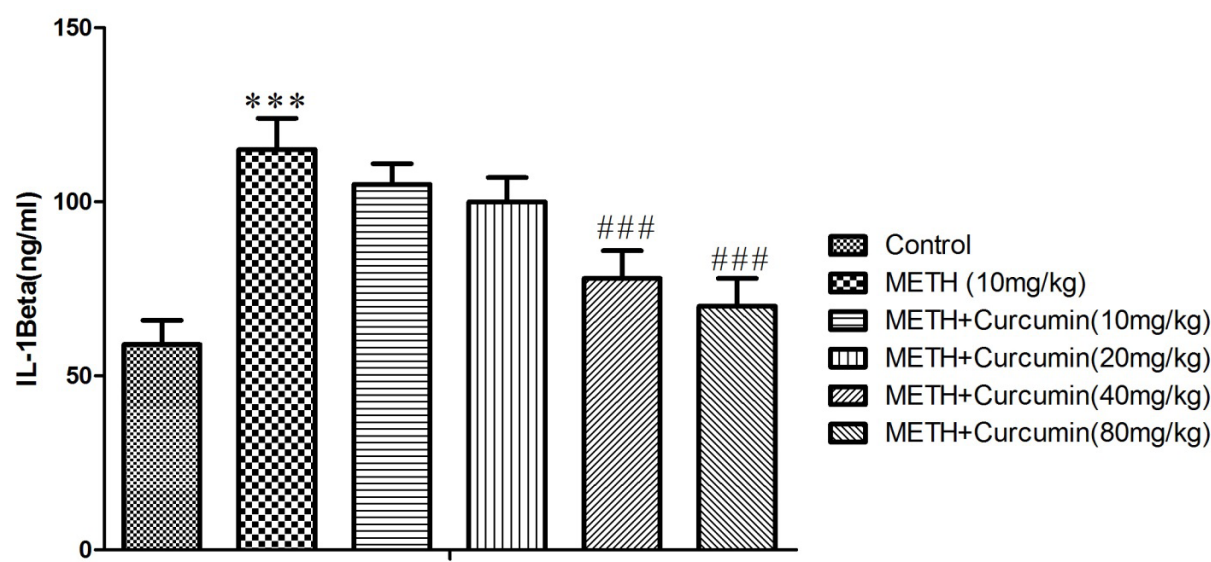

Groups

NEUR SCIENCE

Figure 3. Curcumin diverse doses (10, 20, 40, and $80 \mathrm{mg} / \mathrm{kg}$ ) effect METH-induced changes

A: TNF- $\alpha$; and B: IL-1 $\beta$ levels of rat isolated hippocampus.

All data are expressed as Mean \pm SEM ( $\mathrm{n}=8) ;{ }^{* *+1} \mathrm{P}<0.05$ vs control; ${ }^{\# \# \#} \mathrm{P}<0.05 \mathrm{vs} 10 \mathrm{mg} / \mathrm{kg}$ of Methamphetamine (METH)

TNF-a: Tumor Necrosis Factor-alpha; IL-1ß: Interleukin-1beta.

2005). Our results indicate that high doses of curcumin (40 and $80 \mathrm{mg} / \mathrm{kg}$ ) may have an effect on METH disorder associated with cognition. Several previous studies have shown that curcumin and other herbal compounds can improve learning and memory (Wang et al., 2010). Our findings show that various doses of curcumin can enhance METH caused neuroapoptosis, oxidative stress, and inflammation seen in rat hippocampus.

Here you will find a review on curcumin's effects on the biochemical factors of the hippocampus such as MDA, GSH, GSSG, GPx, GR, SOD, IL- $\beta$, TNF- $\alpha$, Bax, Bcl-2, CREB (total and phosphorylate), and BDNF. We found that administration of METH increases the rate of hippocampal MDA, but treatment with curcumin (10, 20,40 , and $80 \mathrm{mg} / \mathrm{kg}$ ) decreases the risk of brain lipid peroxidation caused by METH. Higher doses of cur- cumin (40 and $80 \mathrm{mg} / \mathrm{kg}$ ) inhibited the MDA level more significantly than the low doses (10 and $20 \mathrm{mg} / \mathrm{kg}$ ). Our results on METH-caused lipid peroxidation in neurodegenerative disorders like Alzheimer's disease (Jiang et al., 2007; Kuhad et al., 2007).

The destructive METH effect is partly due to mitochondrial dysfunction in which curcumin has a partial modulating role (Darvesh et al., 2012; Wang et al., 2010). Previous findings have suggested that neuroprotective curcumin effects are caused by the inhibition of free radical development in neurodegenerative diseases such as Alzheimer's (Jiang et al., 2007; Rajeswari, 2006). Curcumin's key role as a free radical scavenger is fully demonstrated in this type of illness (Rajeswari, 2006). METH $(10 \mathrm{mg} / \mathrm{kg}$ ) has been shown to reduce mitochondrial GSH content and increase GSSG levels in hippo- 

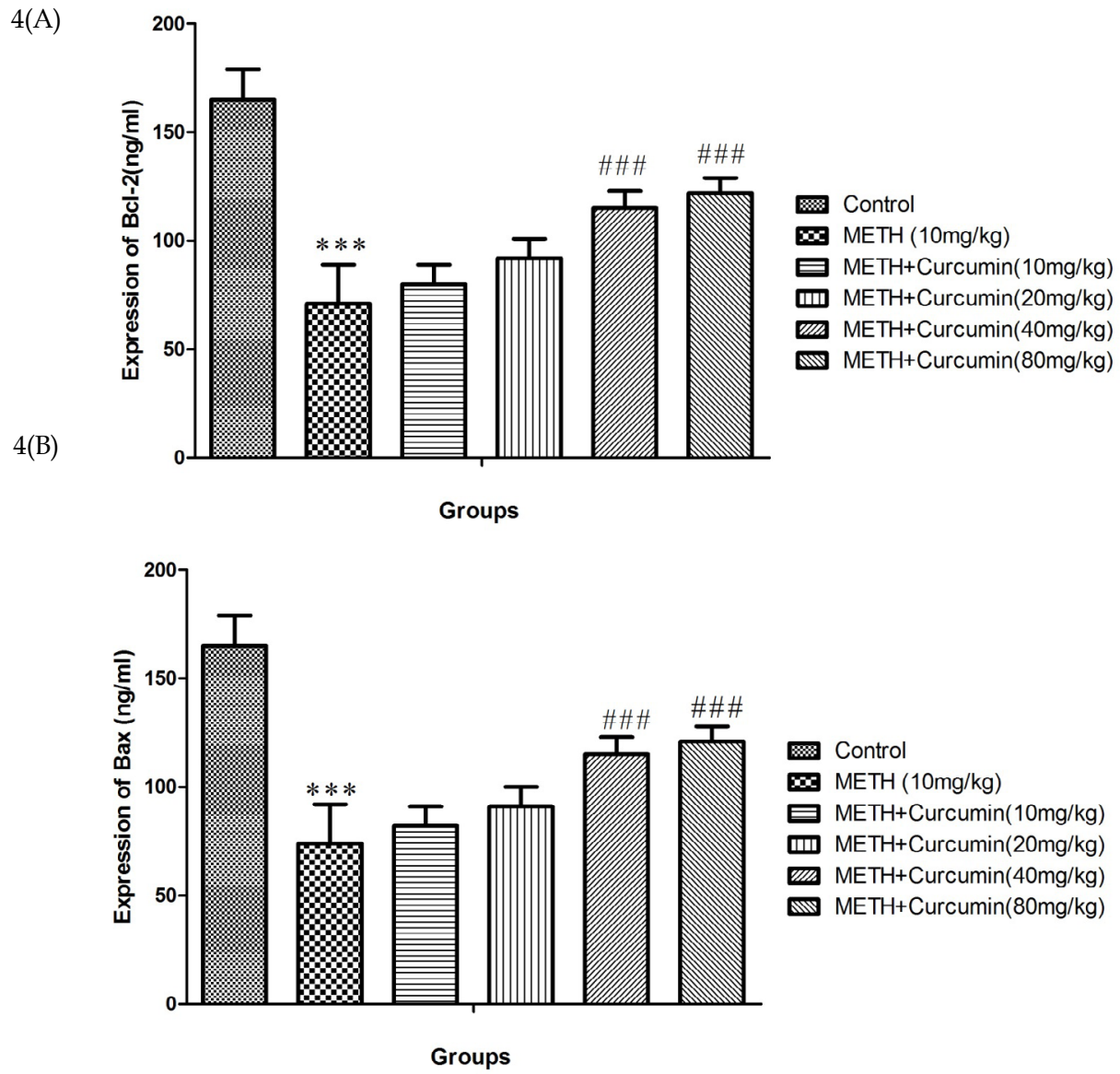

$4(\mathrm{C})$

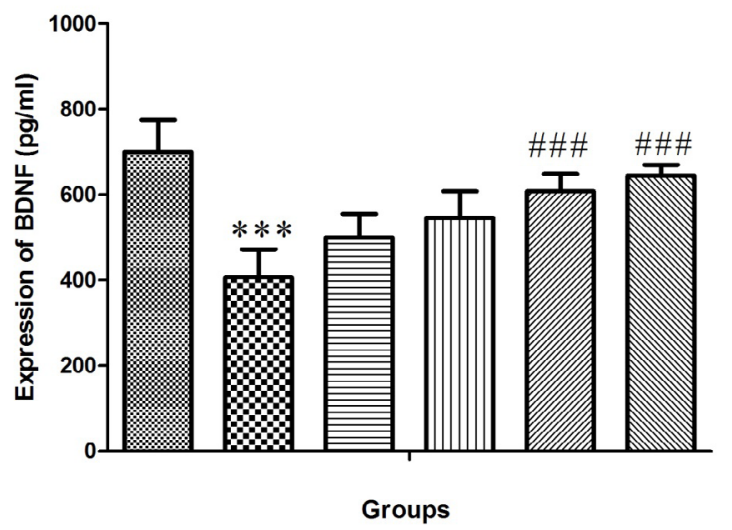

Control

Ex METH $(10 \mathrm{mg} / \mathrm{kg})$

曰 METH+Curcumin $(10 \mathrm{mg} / \mathrm{kg})$

II METH+Curcumin $(20 \mathrm{mg} / \mathrm{kg}$ )

METH+Curcumin $(40 \mathrm{mg} / \mathrm{kg}$ )

METH+Curcumin $(80 \mathrm{mg} / \mathrm{kg})$

$4(\mathrm{D})$

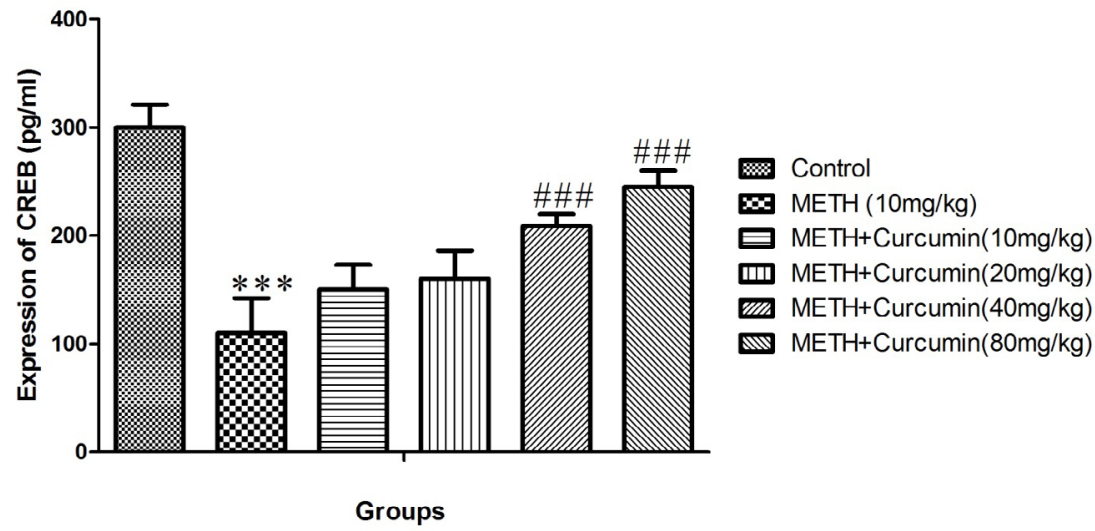


$4(\mathrm{E})$

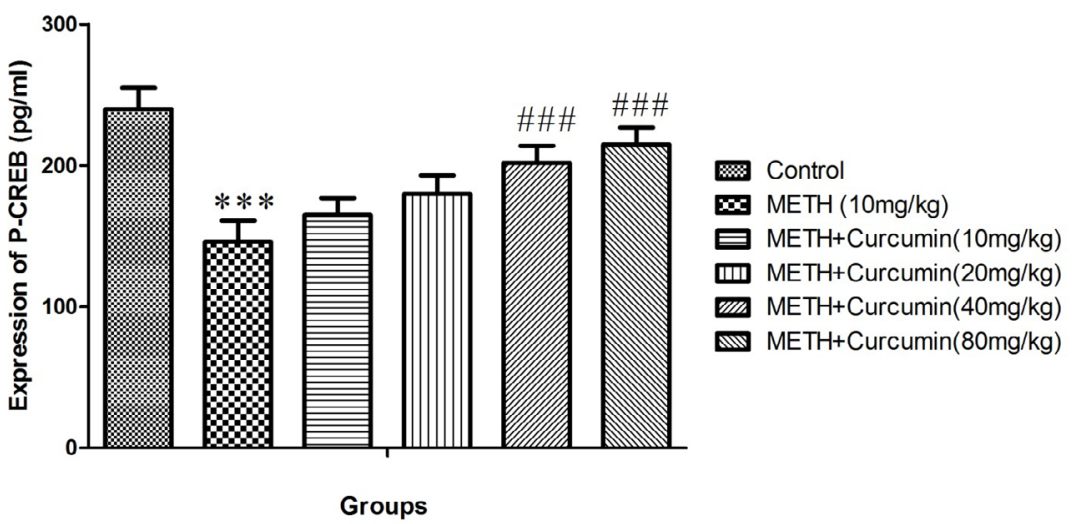

Figure 4. Curcumin diverse doses (10, 20, 40, and $80 \mathrm{mg} / \mathrm{kg}$ ) effect on METH induced changes

NEUR SCIENCE

A: Protein expression of Bax; B: Bcl-2; C: BDNF; D: Total CREB; and E: Phosphorylated CREB in rat isolated hippocampus.

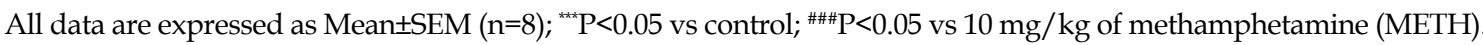

BDNF: Brain-Derived Neurotrophic Factor; CREB: Cyclic AMP Response Element Binding protein.

campal tissues. METH mediates glutathione reduced form (GSH) to toxic oxidized form (GSSG) and plays an important role in starting and activating neurodegenerative brain signals (Griffith \& Meister, 1985; Harold, Wallace, Friedman, Gudelsky \& Yamamoto, 2000; Moszczynska, Turenne \& Kish, 1998; Zitka et al., 2012). Such a harmful mechanism has a destructive effect on the glutathione cycle and results in neural cell death (Griffith \& Meister, 1985; Moszczynska et al., 1998).

Although animals receiving METH $(10 \mathrm{mg} / \mathrm{kg})$ showed reduced GSSG levels, we found that different doses of curcumin, particularly 40 and $80 \mathrm{mg} / \mathrm{kg}$, increased GSH levels. Previous studies have already indicated that curcumin can modulate the glutathione circle and facilitate the production of GSH, which is therapeutically beneficial in neurodegenerative diseases (Rajeswari, 2006; Shin et al., 2007). As confirmed by our research, the METH prescribing reduced GPx, GR and SOD activity of hippocampal differentiated tissues, verifying the findings of preceding studies that the use of METH decreases antioxidant defenses resulting in neurodegeneration (Gonçalves et al., 2010; Imam \& Ali, 2000). GR is the main enzyme in the conversion of the oxidized form of glutathione (GSSG) to reduced form (GSH) (Zhao et al., 2008). Consequently, METH-mediated reduction in GR activity induces GSSG elevation along with GSH reduction, as indicated by our findings.

Many novel studies indicate that METH abuse triggers mitochondrial dysfunction resulting in inhibition of enzymatic antioxidant activity in multiple cells leading to degenerative effects on brain cells such as hippocampus (Cadet et al., 2005; Gonçalves et al., 2010; Motaghinejad et al., 2017). We have shown that the therapeutic doses of curcumin improve enzymatic antioxidant function in a dose-dependent manner. Curcumin stimulates GR to increase the conversion rate of GSSG to GSH and eventually protects the brain against oxidative stress induced by METH. Previous experimental studies have also established the antioxidant properties of curcumin in neurodegenerative disorders and diseases mediated by increasing GR and GPx activity (Shin et al., 2007; Wang et al., 2010).

Our results are also consistent with previous findings on reduced SOD activity following METH abuse (Zhao et al., 2008). In comparison to previous studies, curcumin was shown to reverse alcohol-induced reduction of SOD production in hippocampal tissue (Rajeswari, 2006).

Our research has shown that METH chronic administration significantly increases the levels of pro-inflammatory cytokines such as IL- $\beta$ and TNF- $\alpha$ in hippocampal tissue, whereas high doses of curcumin have a strong dose-dependent suppression effect on METH mediated neuroinflammation. As previously reported, we confirm that the use of METH and other psychostimulant agents would increase pro-inflammatory cytokines. METHinduced upraises in pro-inflammatory biomarkers have been suggested to be in charge of METH neurodegenerative effects (Cadet, Ordonez \& Ordonez, 1997; Deng et al., 2002). Because of the therapeutic effect of curcumin on the neuro-inflammation signaling cascade, it may protect the brain from inflammatory damage (Jiang et al., 2007; Motaghinejad et al., 2015). In addition to oxidative stress and inflammation, we also report apoptosis caused by METH in the hippocampus. Based on our results, the 
administration of METH increased Bax apoptotic protein but decreased Bcl-2 anti-apoptotic protein.

In contrast to our results, previous work indicated that METH abuse causes brain damage through multiple apoptotic cascade activation (Cadet et al., 1997; Deng et al., 2002). Anti-apoptotic effects of curcumin, indicated by Bax reduction and increased levels of Bcl-2 expression have also been reported against METH administration. Previous studies have stated that curcumin has attenuated the effects on cleaved caspase-3, Bax development, and nuclear condensation seen in some neurodegenerative disorders (Motaghinejad et al., 2015; Rajeswari, 2006; Raza et al., 2008).

The results have also demonstrated, as previous studies have shown, the anti-inflammatory, anti-apoptotic and anti-oxidant effects of Curcumin (Raza et al., 2008), whose signaling mechanisms are not yet understood. That is also why we evaluated the signaling pathway P-CREB-BDNF. We find that the protective role of Curcumin is possibly mediated by the signaling pathway P-CREB-BDNF. CREB (total and phosphorylate) and BDNF protein expression in the hippocampus were also reported to increase with METH administration. In contrast, high doses of curcumin increased the expression of CREB (total and phosphorylate) and the protein BDNF. Therefore, we hypothesized that treatment with Curcumin will restore the P-CREB-BDNF signaling cascade to protect the brain against METH-induced neurotoxicity. P-CREB, the transcription factor involved in neuronal regeneration, growth, survival, excitability, addiction, depression and cognition, regulates more than one hundred target genes e.g., BDNF (Carlezon Jr, Duman \& Nestler, 2005). It has also been shown that CREB transcriptional cascade dysregulation induces oxidative stress, apoptosis and neurodegeneration (Carlezon Jr et al., 2005; Mayr \& Montminy, 2001).

Many previous molecular studies have confirmed CREB phosphorylate's leading role in many herbal and chemical Neuroprotective properties (Mayr \& Montminy, 2001). As a number of studies have shown, PCREB (activated form of CREB) plays a positive role in the production of BDNF, the TrkB receptor. They also suggested that BDNF may inhibit neuron-inducing brain cell degeneration by means of receptor-mediated stimulation (TrkB) (Martinowich et al., 2003). We also confirm that METH mediated P-CREB protein reduction affects the signaling pathway for BDNF-TrkB and causes neurodegeneration, apoptosis, inflammation and oxidative stress; while Curcumin administration prevents METH-induced properties from triggering the
P-CREB-BDNF-TrkB cascade. In addition to previous research, we also note that P-CREB-BDNF signaling pathways involved numerous changes in brain functions such as learning, memory, mood fluctuations and reward mechanism (Cao et al., 2013; Martinowich et al., 2003; Yoshii \& Constantine-Paton, 2010).

\section{Conclusion}

We have shown for the first time that curcumin therapy, via P-CREB-BDNF signaling pathway stimulation, could reduce METH-induced apoptosis, oxidative stress, and inflammation by acting as a neuroprotective agent against METH-induced neurodegeneration as a whole. Nevertheless, more research on human dosage and toxicity is required.

\section{Ethical Considerations}

\section{Compliance with ethical guidelines}

This Research was done according to standard animal ethics guidelines of Planning Research and Experimental Procedures on Animals: Recommendations for Excellence (PREPARE) (Smith, Eddie Clutton, Lilley, Hansen \& Brattelid, 2018).This paper was prepared from supplementary data of master of sciences thesis and ethical codes of this thesis and research project are IR.IAU.PS.REC.1398.348.

\section{Funding}

This research was financially supported by the Department of Pharmaceutical Chemistry, Faculty of Pharmaceutical Chemistry, Tehran Medical Sciences, Islamic Azad University, Tehran, Iran.

\section{Authors' contributions}

All authors equally contributed to preparing this article.

\section{Conflict of interest}

The authors declared no conflict of interest.

\section{Acknowledgments}

The authors would like to thank the Head of Research Center of Addiction and Risky Behaviors of Iran University of Medical Sciences and Razi Drug Research Center at the Iran University of Medical Science, Tehran, Iran. 


\section{References}

Arican, O., Aral, M., Sasmaz, S., \& Ciragil, P. (2005). Serum levels of TNF- $\alpha$, IFN- $\gamma$, IL-6, IL-8, IL-12, IL-17, and IL-18 in patients with active psoriasis and correlation with disease severity. Mediators of Inflammation, 2005(5), 201561. [DOI:10.1155/MI.2005.273] [PMID] [PMCID]

Barr, A. M., Panenka, W. J., William MacEwan, G., Thornton, A. E., Lang, D. J., \& Honer, W. G., et al. (2006). The need for speed: An update on methamphetamine addiction. Journal of Psychiatry $\mathcal{E}$ Neuroscience, 31(5), 301-13. [PMID] [PMCID]

Belviranlı, M., Okudan, N., Atalık, K. E. N., \& Öz, M. (2013) Curcumin improves spatial memory and decreases oxidative damage in aged female rats. Biogerontology, 14(2), 187-96. [DOI:10.1007/s10522-013-9422-y] [PMID]

Brecht, M. L., O'Brien, A., von Mayrhauser, Ch., \& Douglas Anglin, M. D. (2004). Methamphetamine use behaviors and gender differences. Addictive Behaviors, 29(1), 89-106. [DOI:10.1016/S03064603(03)00082-0]

Cadet, J. L., Jayanthi, S., \& Deng, X. (2005). Methamphetamineinduced neuronal apoptosis involves the activation of multiple death pathways. Review. Neurotoxicity Research, 8(3-4), 199-206. [DOI:10.1007/BF03033973] [PMID]

Cadet, J. L., Ordonez, S. V., \& Ordonez, J. V. (1997). Methamphetamine induces apoptosis in immortalized neural cells: Protection by the proto-oncogene, bcl-2. Synapse, 25(2), 176-84. [DOI:10.1002/ (SICI)1098-2396(199702)25:2<176::AID-SYN8>3.0.CO;2-9]

Cao, G., Zhu, J., Zhong, Q., Shi, Ch., Dang, Y., \& Han, W., et al. (2013). Distinct roles of methamphetamine in modulating spatial memory consolidation, retrieval, reconsolidation and the accompanying changes of ERK and CREB activation in hippocampus and prefrontal cortex. Neuropharmacology, 67, 144-54. [DOI:10.1016/j.neuropharm.2012.10.020] [PMID] [PMCID]

Carlezon Jr, W. A., Duman, R. S., \& Nestler, E. J. (2005). The many faces of CREB. Trends in Neurosciences, 28(8), 436-45. [DOI:10.1016/j.tins.2005.06.005] [PMID]

Carmena, A., Granado, N., Ares-Santos, S., Alberquilla, S., Tizabi, Y., \& Moratalla, R. (2015). Methamphetamine-induced toxicity in indusium griseum of mice is associated with astro-and microgliosis. Neurotoxicity Research, 27(3), 209-16. [DOI:10.1007/ s12640-014-9505-9] [PMID]

Chen, G., Bower, K. A., Ma, C., Fang, Sh., Thiele, C. J., \& Luo, J. (2004). Glycogen Synthase Kinase $3 \beta$ (GSK3 $\beta$ ) mediates 6-hydroxydopamine-induced neuronal death. The FASEB Journal, 18(10), 1162-4. [DOI:10.1096/fj.04-1551fje] [PMID]

Darke, Sh., Kaye, Sh., McKetin, R., \& Duflou, J. (2008). Major physical and psychological harms of methamphetamine use. Drug and Alcohol Review, 27(3), 253-62. [DOI:10.1080/09595230801923702] [PMID]

Darvesh, A. S. Carroll, R. T., Bishayee, A., Novotny, N. A., Geldenhuys, W. J., \& Van der Schyf, C. J. (2012). Curcumin and neurodegenerative diseases: A perspective. Expert Opinion on Investigational Drugs, 21(8), 1123-40. [DOI:10.1517/13543784.2012.6934 79] [PMID]

Demircan, N., Safran, B. G., Soylu, M., Ozcan, A. A., \& Sizmaz, S. (2006). Determination of vitreous interleukin-1 (IL-1) and Tumour Necrosis Factor (TNF) levels in proliferative diabetic retinopathy. Eye, 20(12), 1366-9. [DOI:10.1038/sj.eye.6702138] [PMID]
Deng, X., Cai, N. Sh., McCoy, M. T., Chen, W., Trush, M. A., \& Cadet J. L. (2002). Methamphetamine induces apoptosis in an immortalized rat striatal cell line by activating the mitochondrial cell death pathway. Neuropharmacology, 42(6), 837-45. [DOI:10.1016/S00283908(02)00034-5]

Gonçalves, J., Baptista, S., Martins, T., Milhazes, N., Borges, F., \& Ribeiro, C. F., et al. (2010). Methamphetamine-induced neuroinflammation and neuronal dysfunction in the mice hippocampus: Preventive effect of indomethacin. European Journal of Neuroscience, 31(2), 315-26. [DOI:10.1111/j.1460-9568.2009.07059.x] [PMID]

Griffith, O. W., \& Meister, A. (1985). Origin and turnover of mitochondrial glutathione. Proceedings of the National Academy of Sciences of the United States of America, 82(14), 4668-72. [DOI:10.1073/ pnas.82.14.4668] [PMID] [PMCID]

Harold, Ch., Wallace, T., Friedman, R., Gudelsky, G., \& Yamamoto B. (2000). Methamphetamine selectively alters brain glutathione European Journal of Pharmacology, 400(1), 99-102. [DOI:10.1016/ S0014-2999(00)00392-7]

Hattiangady, B., Rao, M. S., Shetty, G. A., \& Shetty, A. K. (2005) Brain-derived neurotrophic factor, phosphorylated cyclic AMP response element binding protein and neuropeptide $Y$ decline as early as middle age in the dentate gyrus and CA1 and CA3 subfields of the hippocampus. Experimental Neurology, 195(2), 353-71 [DOI:10.1016/j.expneurol.2005.05.014] [PMID]

Imam, S. Z., \& Ali, S. F. (2000). Selenium, an antioxidant, attenuates methamphetamine-induced dopaminergic toxicity and peroxynitrite generation. Brain Research, 855(1), 186-91. [DOI:10.1016/ S0006-8993(99)02249-0]

Jiang, J., Wang, W., Sun, Y. J., Hu, M., Li, F., \& Zhu, D. Y. (2007) Neuroprotective effect of curcumin on focal cerebral ischemic rats by preventing blood-brain barrier damage. European Journal of Pharmacology, 561(1-3), 54-62. [DOI:10.1016/j.ejphar.2006.12.028] [PMID]

Johnson, B. A., Roache, J. D., Ait-Daoud, N., Wallace, Ch., Wells, L. T., \& Wang, Y. (2005). Effects of isradipine on methamphetamineinduced changes in attentional and perceptual-motor skills of cognition. Psychopharmacology, 178(2-3), 296-302. [DOI:10.1007/ s00213-004-1998-0] [PMID]

Jumnongprakhon, P., Govitrapong, P., Tocharus, Ch., \& Tocharus, J. (2016). Melatonin promotes blood-brain barrier integrity in methamphetamine-induced inflammation in primary rat brain microvascular endothelial cells. Brain Research, 1646, 182-92. [DOI:10.1016/j.brainres.2016.05.049]

Kim, H. (2005). Neuroprotective herbs for stroke therapy in traditional eastern medicine. Neurological Research, 27(3), 287-301. [DOI:10.1179/016164105X25234] [PMID]

Kuhad, A., Pilkhwal, S., Sharma, S., Tirkey, N., \& Chopra, K. (2007) Effect of curcumin on inflammation and oxidative stress in cisplatin-induced experimental nephrotoxicity. Journal of Agricultural and Food Chemistry, 55(25), 10150-5. [DOI:10.1021/jf0723965] [PMID]

Lee, B. H., Kim, H., Park, S. H., \& Kim, Y. K. (2007). Decreased plasma BDNF level in depressive patients. Journal of Affective Disorders, 101(1-3), 239-44. [DOI:10.1016/j.jad.2006.11.005] [PMID]

Lee, J., Kim, C. H., Simon, D. K., Aminova, L. R., Andreyev, A. Y, \& Kushnareva, Y. E., et al. (2005). Mitochondrial cyclic AMP response element-binding protein (CREB) mediates mitochondrial gene expression and neuronal survival. Journal of Biological Chemistry, 280(49), 40398-401. [DOI:10.1074/jbc.C500140200] [PMID] [PMCID] 
Levi, M. S., Divine, B., Hanig, J. P., Doerge, D. R., Vanlandingham, M. M., \& George, N. I., et al. (2012). A comparison of methylphenidate-, amphetamine-, and methamphetamine-induced hyperthermia and neurotoxicity in male Sprague-Dawley rats during the waking (lights off) cycle. Neurotoxicology and Teratology, 34(2), 253-62. [DOI:10.1016/j. ntt.2012.01.007] [PMID]

Martinowich, K., Hattori, D., Wu, H., Fouse, Sh., He, F., \& Hu, Y., et al. (2003). DNA methylation-related chromatin remodeling in activity-dependent Bdnf gene regulation. Science, 302(5646), 890-3. [DOI:10.1126/science.1090842] [PMID]

Mayr, B., \& Montminy, M. (2001). Transcriptional regulation by the phosphorylation-dependent factor CREB. Nature Reviews Molecular Cell Biology, 2(8), 599-609. [DOI:10.1038/35085068] [PMID]

Moszczynska, A., Turenne, S., \& Kish, S. J. (1998). Rat striatal levels of the antioxidant glutathione are decreased following binge administration of methamphetamine. Neuroscience Letters, 255(1), 49-52. [DOI:10.1016/S0304-3940(98)00711-3]

Motaghinejad, M., Karimian, M., Motaghinejad, O., Shabab, B., Yazdani, I., \& Fatima, S. (2015). Protective effects of various dosage of Curcumin against morphine induced apoptosis and oxidative stress in rat isolated hippocampus. Pharmacological Reports, 67(2), 230-5. [DOI:10.1016/j. pharep.2014.09.006] [PMID]

Motaghinejad, M., Motevalian, M., Abdollahi, M., Heidari, M., \& Madjd, Z. (2017). Topiramate confers neuroprotection against methylphenidate-induced neurodegeneration in dentate gyrus and CA1 regions of Hippocampus via CREB/ BDNF pathway in rats. Neurotoxicity Research, 31(3), 373-99. [DOI:10.1007/s12640-016-9695-4] [PMID]

Motaghinejad, M., Motevalian, M., Babalouei, F., Abdollahi, M., Heidari, M., \& Madjd, Z. (2017). Possible involvement of CREB/BDNF signaling pathway in neuroprotective effects of topiramate against methylphenidate induced apoptosis, oxidative stress and inflammation in isolated hippocampus of rats: Molecular, biochemical and histological evidences. Brain Research Bulletin, 132, 82-98. [DOI:10.1016/j.brainresbull.2017.05.011] [PMID]

Motaghinejad, M., Motevalian, M., Fatima, S., Beiranvand, T., \& Mozaffari, Sh. (2017). Topiramate via NMDA, AMPA/ kainate, $\mathrm{GABA}_{\mathrm{A}}$ and Alpha2 receptors and by modulation of CREB/BDNF and Akt/GSK3 signaling pathway exerts neuroprotective effects against methylphenidate-induced neurotoxicity in rats. Journal of Neural Transmission, 124(11), 1369-87. [DOI:10.1007/s00702-017-1771-2] [PMID]

Motaghinejad, M., Motevalian, M., Fatima, S., Faraji, F., \& Mozaffari, Sh. (2017). The neuroprotective effect of curcumin against nicotine-induced neurotoxicity is mediated by CREB-BDNF signaling pathway. Neurochemical Research, 42(10), 2921-32. [DOI:10.1007/s11064-017-2323-8] [PMID]

Motaghinejad, M., Motevalian, M., Fatima, S., Hashemi, H., \& Gholami, M. (2017). Curcumin confers neuroprotection against alcohol-induced hippocampal neurodegeneration via CREBBDNF pathway in rats. Biomedicine \& Pharmacotherapy, 87, 72140. [DOI:10.1016/j.biopha.2016.12.020] [PMID]

Motaghinejad, M., Seyedjavadein, Z., Motevalian, M., \& Asadi, M. (2016). The neuroprotective effect of lithium against high dose methylphenidate: Possible role of BDNF. NeuroToxicology, 56, 40-54. [DOI:10.1016/j.neuro.2016.06.010] [PMID]
Narita, M., Aoki, K., Takagi, M., Yajima, Y., \& Suzuki, T. (2003). Implication of brain-derived neurotrophic factor in the release of dopamine and dopamine-related behaviors induced by methamphetamine. Neuroscience, 119(3), 767-75. [DOI:10.1016/ S0306-4522(03)00099-X]

Phani Kumar, G., \& Khanum, F. (2012). Neuroprotective potential of phytochemicals. Pharmacognosy Reviews, 6(12), 81-90 [DOI:10.4103/0973-7847.99898] [PMID] [PMCID]

Rajeswari, A. (2006). Curcumin protects mouse brain from oxidative stress caused by 1-methyl-4-phenyl-1, 2, 3, 6-tetrahydropyridine. European Review for Medical and Pharmacological Sciences, 10(4), 157-61. [PMID]

Raza, H., John, A., Brown, E. M., Benedict, Sh., \& Kambal, A. (2008). Alterations in mitochondrial respiratory functions, redox metabolism and apoptosis by oxidant 4-hydroxynonenal and antioxidants curcumin and melatonin in PC12 cells. Toxicology and Applied Pharmacology, 226(2), 161-8. [DOI:10.1016/j. taap.2007.09.002] [PMID]

Shi, Y. Q., Huang, T. W., Chen, L. M., Pan, X. D., Zhang, J., \& Zhu, Y. G., et al. (2010). Ginsenoside Rg1 attenuates amyloid- $\beta$ content, regulates PKA/CREB activity, and improves cognitive performance in SAMP8 mice. Journal of Alzheimer's Disease, 19(3), 977-89. [DOI:10.3233/JAD-2010-1296] [PMID]

Shin, H. J., Lee, J. Y., Son, E., Lee, D. H., Kim, H. J., \& Kang, S. $\mathrm{S}$., et al. (2007). Curcumin attenuates the kainic acid-induced hippocampal cell death in the mice. Neuroscience Letters, 416(1), 49-54. [DOI:10.1016/j.neulet.2007.01.060] [PMID]

Smith, A. J., Eddie Clutton, R., Lilley, E., Hansen, K. E. A., \& Brattelid, T. (2018). PREPARE: Guidelines for planning animal research and testing. Laboratory Animals, 52(2), 135-41. [DOI:10.1177/0023677217724823] [PMID] [PMCID]

Thrash, B., Karuppagounder, S. S., Uthayathas, S., Suppiramaniam, V., \& Dhanasekaran, M. (2010). Neurotoxic effects of methamphetamine. Neurochemical Research, 35(1), 171-9. [DOI:10.1007/s11064-009-0042-5] [PMID]

Tiwari, V., \& Chopra, K. (2012). Attenuation of oxidative stress, neuroinflammation, and apoptosis by curcumin prevents cognitive deficits in rats postnatally exposed to ethanol. Psychopharmacology, 224(4), 519-35. [DOI:10.1007/ s00213-012-2779-9] [PMID]

Volkow, N. D., Chang, L., Wang, G. J., Fowler, J. S., LeonidoYee, M., \& Franceschi, D., et al. (2001). Association of dopamine transporter reduction with psychomotor impairment in methamphetamine abusers. American Journal of Psychiatry, 158(3), 377-82. [DOI:10.1176/appi.ajp.158.3.377] [PMID]

Vorhees, Ch. V., \& Williams, M. T. (2006). Morris water maze: Procedures for assessing spatial and related forms of learning and memory. Nature Protocols, 1(2), 848-58. [DOI:10.1038/nprot.2006.116] [PMID] [PMCID]

Wang, R., Li, Y. H., Xu, Y., Li, Y. B., Wu, H. L., \& Guo, H., et al. (2010). Curcumin produces neuroprotective effects via activating brain-derived neurotrophic factor/TrkB-dependent MAPK and PI-3K cascades in rodent cortical neurons. Progress in Neuro-Psychopharmacology and Biological Psychiatry, 34(1), 147-53. [DOI:10.1016/j.pnpbp.2009.10.016] [PMID]

Wu, C. W., Ping, Y. H., Yen, J. Ch., Chang, Ch. Y., Wang, Sh. F., \& Yeh, Ch. L., et al. (2007). Enhanced oxidative stress and aberrant mitochondrial biogenesis in human neuroblastoma SH-SY5Y cells during methamphetamine induced apoptosis. Toxicology and Applied Pharmacology, 220(3), 243-51. [DOI:10.1016/j.taap.2007.01.011] [PMID] 
Yadav, R. S., Shukla, R. K., Sankhwar, M. L., Patel, D. K., Ansari, R. W., \& Pant, A. B., et al. (2010). Neuroprotective effect of curcumin in arsenic-induced neurotoxicity in rats. $\mathrm{Neu}$ roToxicology, 31(5), 533-9. [DOI:10.1016/j.neuro.2010.05.001] [PMID]

Yamamoto, B. K., \& Raudensky, J. (2008). The role of oxidative stress, metabolic compromise, and inflammation in neuronal injury produced by amphetamine-related drugs of abuse. Journal of Neuroimmune Pharmacology, 3(4), 203-17. [DOI:10.1007/s11481-008-9121-7] [PMID] [PMCID]

Yoshii, A., \& Constantine-Paton, M. (2010). Postsynaptic BDNF-TrkB signaling in synapse maturation, plasticity, and disease. Developmental Neurobiology, 70(5), 304-22. [DOI:10.1002/dneu.20765] [PMID] [PMCID]

Zbarsky, V., Datla, K. P., Parkar, Sh., Rai, D. K., Aruoma, O. I., \& Dexter, D. T. (2005). Neuroprotective properties of the natural phenolic antioxidants curcumin and naringenin but not quercetin and fisetin in a 6-OHDA model of Parkinson's disease. Free Radical Research, 39(10), 1119-25. [DOI:10.1080/10715760500233113] [PMID]

Zhang, X., Banerjee, A., Banks, W. A., \& Ercal, N. (2009). NAcetylcysteine amide protects against methamphetamineinduced oxidative stress and neurotoxicity in immortalized human brain endothelial cells. Brain Research, 1275, 87-95. [DOI:10.1016/j.brainres.2009.04.008] [PMID] [PMCID]

Zhao, J., Yu, Sh., Zheng, W., Feng, G., Luo, G., \& Wang, L., et al. (2010). Curcumin improves outcomes and attenuates focal cerebral ischemic injury via antiapoptotic mechanisms in rats. Neurochemical Research, 35(3), 374-9. [DOI:10.1007/ s11064-009-0065-y] [PMID]

Zhao, J., Zhao, Y., Zheng, W., Lu, Y., Feng, G., \& Yu, Sh. (2008). Neuroprotective effect of curcumin on transient focal cerebral ischemia in rats. Brain Research, 1229, 224-32. [DOI:10.1016/j.brainres.2008.06.117] [PMID]

Zitka, O., Skalickova, S., Gumulec, J., Masarik, M., Adam, V., \& Hubalek, J., et al. (2012). Redox status expressed as GSH: GSSG ratio as a marker for oxidative stress in paediatric tumour patients. Oncology Letters, 4(6), 1247-53. [DOI:10.3892/ ol.2012.931] [PMID] [PMCID] 